Egypt. Acad. J. Biolog. Sci., 4(1): 87-95 (2012)

Email: egyptianacademic@yahoo.com

Received: $21 / 6 / 2012$
C. Physiology \& Molecular Biology

ISSN: 2090-0767

www.eajbs.eg.net

\title{
“Gari” Solution on endurance ability: an interventional study among school children in ilorin metropolis, nigeria
}

\author{
Bakinde, Surajudeen Tosho, Talabi, Adetayo Ebun, Olaitan, Olukunmi 'Lanre, \\ Department of Human Kinetics and Health Education University of Ilorin, Nigeria \\ Email: lanreolives@yahoo.com \\ OR: olaitan.ol@unilorin.edu.ng
}

\section{ABSTRACT}

This research study investigated the effect of concentrations of “Gari” solution on endurance ability of school children in Ilorin metropolis, Nigeria. The design of the study was experimental that involves the manipulation of a particular variable. In order to provide solution to the research problem, four hypotheses were drawn. Forty[40] subjects were randomly selected as sample from four male secondary schools in Ilorin metropolis and they are those that are not actively involved in sports, but within the age limit of 12-13 years. Standardized instruments were used for both the experimental and control groups. The results of the experimental groups showed a significant difference on the effect of concentrations of "gari" solution on endurance ability of school children in Ilorin metropolis within 6\%, 7\%, and 8\% respectively. The three groups with treatment improved tremendously on their performance over the result of the post-test and that of the control group. This showed that each percentage of the treatment has improved the performances ability of the school children in endurance activities of $4 \mathrm{~km}$ run/walk. Based on the finding, it was recommended among others that, coaches, athletes and others involved in endurance activities should cultivate habit of taking "gari" solution to enhance their performances.

Keywords: “Gari" solution, endurance ability, performance, school children, carbohydrates, electrolyte

\section{INTRODUCTION}

Proper nutrition forms the foundation for physical performance, because it provides both the fuel for biological work and the chemicals for extracting and using the potential energy contained within this fuel.

Nigeria is fast becoming a sport loving nation and as such a lot of people have taken to sports for a lot of reasons such as a unifying factor, political integration, as a medium of communication, job opportunities and fitness for individuals (Adeniyi, 1990). Cassava as a basic energy source for human food and "Gari" being one of its product is a well-known west Africa food (Nigeria), it is obtained by first grating fresh peeled cassava roots, allowing the mash to ferment for 2-5 days and squeezing the fermented mash to reduce its moisture content, before roasting the dewatered mash on a hot flat surface. Gari is a free-flowing granular meal which is consumed in a variety of ways (Cook, 2005).

One of such areas where a solution can and should be found is the area of electrolyte drinks, which are vital to athlete performance. Electrolyte drinks help to prolong capacity for physical exercises which help spare muscle glycogen and delay or prevent low blood sugar levels, and consequently help to reduce or delay fatigue (Sloan (2005), Fox (2009), Nancy (1990), Talabi, (2001)). It also helps to keep the body in fluid balance (Nancy, 2006). Electrolyte 
drinks are drinks, which are vital to athlete performance especially in the humid tropics nation such as Nigeria, where high temperature is coupled with high humidity. These lead to a situation where excessive amount of water and electrolytes are lost in the body due to excessive sweating (Talabi, 2001).

Endurance activities or those expending large amounts of energy for a long time need an electrolyte fluid which contain $60 \%$ to $70 \%$ calories and minerals, which can provide an advantage during exercise by keeping the body energized and mineralized so that it is able to concentrate better. This is because sweat lost contains not only water but also small amounts of sodium, potassium and other electrolytes that help to keep body in fluid balance (Coggan. \& Swanson, 2002, Nancy, 2006).

\section{Effect of Carbohydrate on Endurance Performances}

The body requires a certain number of essential nutrients to function satisfactorily. These include protein, carbohydrate, minerals, vitamins and water, while the carbohydrates, fats, and proteins can be supplied by relatively few natural food, a larger collections may be needed to supply the mineral and vitamin requirements, as there are about twenty vitamins and seventeen minerals believed to be active in human nutrition (Talabi, 2000).

Since energy demands of athlete depend on the intensity of the muscle work and duration of event, athlete involved in event of short duration needs little amount of carbohydrate because, it is the most efficient source of energy and it is readily absorbed from the stomach, unlike food that is high in fat and protein.

People who take very little exercise need about 1500-2500 calories per day; just sitting down, or even sleeping uses up some energy. More active adults need around 2500-3000 calories per day to maintain a normal weight. Men usually need more energy than women. The more active one is, the more energy is needed. Endurance athletes use 5000 or more calories a day. Brewer, Williams and Patton, (2008) asserted that it is more important to get this extra energy by increasing carbohydrate intake than by eating more fat or protein, because most athletes get as much as $60-70 \%$ of their energy from carbohydrates (Brewer, et al, 2008, Marieb, 2009).

The primary purpose of carbohydrate ingestion during continuous strenuous exercise is to maintain blood glucose concentration and maintain carbohydrate oxidation during the latter stages of prolonged exercise (Coggan, et al. 2011). As a result, subjects can exercise longer and sprint faster at the end of exercise. Most studies demonstrating improved performance have given subject 25-60g of carbohydrate per hour of exercise although some have given more (American College of Sport Medicine, 1991, Sawka, Knowlton and Critz, 2009). Coyle, et al. (2011) therefore recommended that individuals consume solutions which provide $30-60 \mathrm{~g}$ of carbohydrate per hour in the form of glucose, sucrose or starch. It should be realized that solid carbohydrate feedings in the form of food containing sucrose or starch can probably also supply the carbohydrate needs of exercise (Fielding, Costill, Fink, King, Hargreaves and Kovaleski, 2005). However, most athletes prefer to drink rather than eat carbohydrate during exercise.

\section{Cassava Solution as a Possible Glucose-Electrolyte Solution for Endurance Sports.}

Cassava-Manihot esculenta Crantz (syn. Manihot Utilissima Polm), a dicotyledonous perennial plant belonging to the botanical family Euphorbiaccae, is an important root crop in Nigeria. It is a starchy root crop which grows almost entirely in the hotter lowland tropics.

The crop is also known under a variety of names according to the region 
in which it is cultivated; cassava in the English-speaking countries of north America, Europe and Africa, manioc in French-speaking countries, tapioca in the English-speaking countries of South East Asia, mandioca in Brazil and Yuka in the Spanish-speaking countries of South America (Asiedu, 2009).

\section{Gari}

Gari can be considered to be the most popular form in which cassava is consumed in West Africa. Cassava is processed into gari in the following ways. The harvested roots are peeled, washed and then grated. The resulting pulp is put into a cloth bag and subjected to pressure by heaping stones on the bag. After pressing, the bag is left for 2-4days, during which time the pulp ferments. Most of the juice from the cassava pulp is expressed from the bag, during this period. The fermented pulp is then removed from the bag, sieved and roasted or fried in wide, shallow metal pans, until dry .The processing of cassava into "Gari" involves several unit operations: peeling, washing, grating, pressing, fermenting, sieving, roasting and drying.

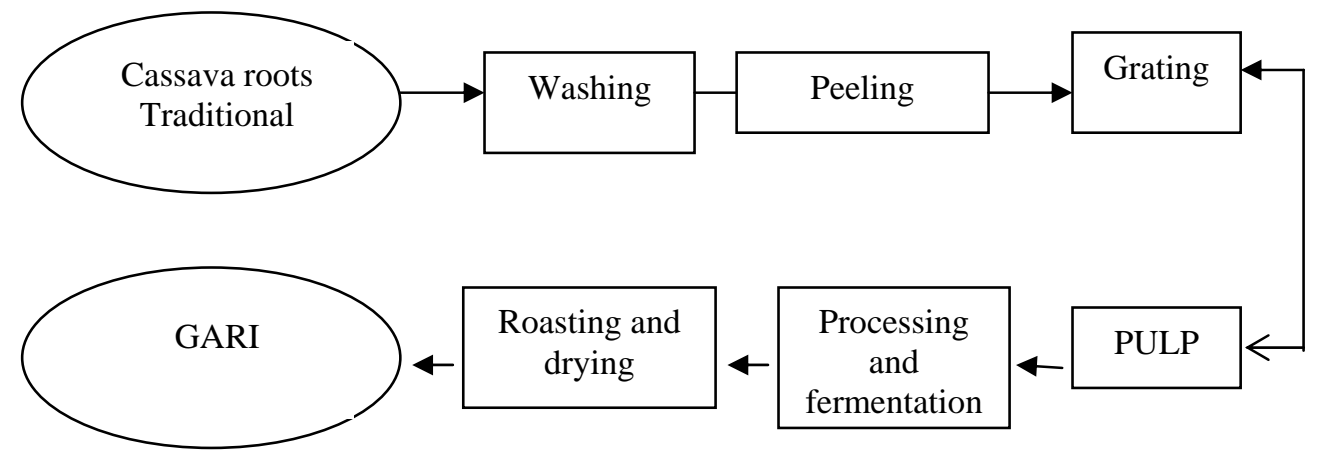

Fig. 1: Flow chart for gari processing in rural areas of West Africa (Source: The authors, 2011)

"Gari” production is laborious and time-consuming; on average it takes about 90 hours to process $100 \mathrm{~kg}$ of gari. About 65 percent of the total time is spent on peeling a 25 percent on roasting. "Gari" occupies an important place in the diets of the people of West Africa. It is customarily consumed in the form of meal, which is prepared by soaking the "gari" in water to swell the starch, and by making the swollen meal into dough. The dough is then made into a ball with the fingers and is dipped into stew containing ingredients such as palm oil, vegetables, meat or fish. Gari may also be eaten without a stew or soup by soaking it in cold water and adding sugar or milk.

Table 1: Nutrient composition of Cassava Meal of feed ingredients.

\begin{tabular}{|c|c|c|c|c|c|c|c|c|c|}
\hline Ingredient & $\begin{array}{c}\text { Dry } \\
\text { matter } \\
\text { (DM\%) }\end{array}$ & $\begin{array}{c}\text { Crude } \\
\text { protein } \\
\%\end{array}$ & $\begin{array}{c}\text { energy } \\
\text { Mek } \\
\text { Cal/kg }\end{array}$ & $\begin{array}{c}\text { ether } \\
\text { extra } \\
\text { (ou)\% }\end{array}$ & $\begin{array}{c}\text { Crude } \\
\text { fibre } \\
\%\end{array}$ & $\begin{array}{c}\text { Lysine } \\
\%\end{array}$ & $\begin{array}{c}\text { Methlomine } \\
\%\end{array}$ & $\begin{array}{c}\text { Calcium } \\
\%\end{array}$ & $\begin{array}{c}\text { Phosphorus } \\
\text { available } \\
\%\end{array}$ \\
\hline Cassava Meal & 90 & 2.5 & 3200 & 0.50 & 3.50 & 0.07 & 0.03 & 0.20 & 0.03 \\
\hline
\end{tabular}

(Source: Nutrient Master, 2011).

It is the opinion of the researchers that a very good electrolyte drink can be made from cassava (gari) solution. This may however need more mineralization to cater for the mineral deficiencies especially that of potassium, sodium and chloride, ions.

\section{Purpose of the study}

The main purpose of this study was to examine the effect of electrolytes solution prepared from cassava on endurance capacity of school age children, with the view of providing information on the effectiveness of "gari" 
solution as a means of providing supplementation during athletic event.

Table 2: Composition of peeled cassava tubers

\begin{tabular}{|l|l|l|}
\hline \multicolumn{1}{|c|}{ Constituent } & Fresh Basis( \%) & \multicolumn{1}{|c|}{ Dry matter Basis(\%) } \\
\hline Water & 66.2 & - \\
Starch & 27.5 & 81.5 \\
Sucrose & 1.0 & 3.0 \\
Glucose & 0.4 & 1.1 \\
Fructose & 0.3 & 0.8 \\
Protein & 0.4 & 1.3 \\
Fats & 0.2 & 0.6 \\
Minerals & 0.8 & 2.5 \\
Dietary fibre & 1.5 & 4.3 \\
Remainder & 1.7 & 4.9 \\
\hline Cyanide (HCN) (PPM) & $150-300$ & $300-900$ \\
\hline
\end{tabular}

Sources: Karim and Fasasi (2009).

\section{Research questions}

1. Will intake of "Gari" solution have effect on the pre and post performance of the experimental group A in $4 \mathrm{~km}$ run/walk?

2. Will intake of "Gari" solution have effect on the pre and post test performance of the experimental group B in $4 \mathrm{~km}$ run/walk?

3. Will intake of "Gari" solution have effect on the pre and post test performance of the experimental group $\mathrm{C}$ in $4 \mathrm{~km}$ run/walk?

\section{Research hypotheses:}

1. "Gari" solution will not have any significant effect on the pre and post test endurance performance of the experimental group $\mathrm{A}$ in $4 \mathrm{~km}$ run/walk.

2. "Gari" solution will not have any significant effect on the pre and post test endurance performance of the experimental group $B$ in $4 \mathrm{~km}$ run/walk.

3. "Gari" solution will not have any significant effect on the pre and post test endurance performance of the experimental group $\mathrm{C}$ in $4 \mathrm{~km}$ run/walk.

4. There will be no significant difference in the pre and post test endurance performance of the control group in $4 \mathrm{~km}$ run/walk.

\section{MATERIALS AND METHODS}

This study adopted a quasi experimental research design (Araoye, 2003). It was equally an experimental study that involves the manipulation of a particular variable which is concentration of gari solution in pre and post-test situation. The population selected was male junior secondary school children in Ilorin metropolis within the age range of 12-13years of age. The subjects used in this study were 40 male students who volunteered from four secondary schools in Ilorin metropolis which are Government Secondary School (GSS) Ilorin; Mount Carmel College (MCC) Ilorin; Government Day Secondary School (GDSS) Fate Ilorin and Government Technical College (GTC) Ilorin. The subjects used were randomly selected through balloting from the number of the volunteer students. The subjects selected were those not actively involved in sports, within the age limit of 10-13 years in the Junior Secondary Schools (JSS). The tools used in this study were standardized instruments, such as; stop watches, starting gun, kitchen scale, standard stadium athletic track, and gari solution- this is a specially prepared solution which was given to the children under the experimental groups. There were three different (A, B, C) solutions for experimental groups. Gari solutions used were 60 grams $/ 1000 \mathrm{ML}$ for group $\mathrm{A}$, 
70grams/1000ML for group B and 80 grams $/ 1000 \mathrm{ml}$ for group C. Coyle and Montain (2002) observed that 6\% to $8 \%$ carbohydrate solution allows easy gastric emptying which is the best for adequate fluid replacement.

The gari solution was prepared and served one hour (1hr) before the commencement of the race. This allowed the gari to dissolve properly before the race. The gari solution was properly stirred together and the particles removed. An interval of 30 minutes was allowed between when the drink was taken and the commencement of the post test race (Coggan and Swanson, 2002).

The researchers and 6 trained research assistants were involved in carrying out the experiment involving 40 male students. The research assistants were used to prepare, guide and render assistance to both the researchers and the subjects. Subjects were randomly divided into four groups (10 per group).

Before the commencement of the race, four different jars of solution were made available. The jars were labeled to reflect the four groups of the already divided students. For the pre-test race only water was put into all the four jars for subjects to take. Only between 600$1250 \mathrm{ml}$ of water was allowed for each subject, since the race is expected to finish before 60 minutes. American College of Sports medicine (2005), agreed that the liquid solution to be taken should be within $600-1250 \mathrm{ml} \mathrm{h}^{-1}$. Subjects were told about the content of the solution in post test races.

For the post-test three different concentrations of "Gari" solution were made available for the experimental group while the controlled group was made to drink ordinary water. An interval of one week was between the pre and post test race, so as to allow the subjects to recover fully from the stress of the previous pretest.

A warm up of 10-15 minutes was allowed for each subject before the commencement of either the pre or post test. Activities for the warm up were limited to stretches and short exercises. Subjects were advised not to eat any food before coming for the pre and post test race. This is because if a high carbohydrate diet precedes athletic activity, the type of sports drink ingested may not have effect on the performance improvement.

Coyle and Montain (2002) advised that carbohydrate solution should be between $6 \%$ to $8 \%$ concentration, because this is the concentration that is best for gastric emptying for most people.

Solution A contained 60grams/ $1000 \mathrm{ml}$ which gave $6 \%$ concentration of gari solution was given to experimental group $\mathrm{A}$.

Solution B contained 70grams / $1000 \mathrm{ml}$ which gave $7 \%$ concentration of gari in solution was for experimental group B.

Solution C contained 80grams/ $1000 \mathrm{ml}$ which gave $8 \%$ concentration of gari in solution was used for experimental group $\mathrm{C}$. where as solution D contained only water for the control group.

Even though the instruments for this study are already standardized and validated, the researchers conducted a pilot test on 8 subjects; this was used to familiarize the researchers and the research assistants on testing procedure. During the post test race, the four groups were balloted into the three specially prepared gari solutions (experimental groups) and the water solution (control group).The race was done very early in the morning between 8 and 10 a.m. The four different groups were lined up behind the four different solutions, thirty minutes before the commencement of the race. Only between $600-1250 \mathrm{mls}$ of the solutions were allowed for each subject to drink before the commencement of the race. 
All the four groups of drinks and subjects were distinctly labeled for proper identifications. The entire group started the race at the same time and place. The time returned for each subject was recorded and placed in the appropriate groups for group analysis of the results. During the one week interval between pre and post-test subjects were advised not to do any activities that are different from their daily routine.

The data collected in the study was treated with descriptive statistics of mean and standard deviation. Also, inferential statistics of $t$-test was used to compare the pre test and post test scores at 0.05 level of significance.

\section{RESULTS}

Table 3 shows that respondents were equally sampled from the four secondary schools as follows; 25\% apiece from GSS, Ilorin, MCC, Ilorin, GSS, Fate, Ilorin and GTC, Ilorin. 45\% of the respondents are in JSS III, 30\% in JSS II and25\% in JSS I. Whereas, 55\% are within ages 12 - 13 years and $45 \%$ are within age $10-11$ years.

Table 3: Bio-data of respondent in percentages

\begin{tabular}{lcc}
\hline Characteristics & Frequency/No. & Percentage (\%) \\
\hline School & 10 & 25 \\
GSS, Ilorin & 10 & 25 \\
MCC, Ilorin & 10 & 25 \\
GDSS, Fate, Ilorin & 10 & 25 \\
GTC, Ilorin & 40 & 100 \\
Total & & \\
Class & 10 & 25 \\
JSS I & 12 & 30 \\
JSS II & 18 & 45 \\
JSS III & 40 & 100 \\
Total & 18 & 45 \\
Age (In years) $10-11$ & 22 & 55 \\
12 - 13 & 40 & 100 \\
\hline Total & &
\end{tabular}

From the Table 4, it is clear that the group C with 8\%"gari" solution returned the least time of 7.28 minutes for the post-test $4 \mathrm{~km}$ run/walk. This is followed by group B (7\% "Gari” concentration) with a time of 7.40 minutes and group $A$
(6\% "gari" concentration) with a time of 7.63 minutes. The control group D with 0\%"gari" concentration returned the highest post-test run score of 8.15minutes.

Table 4: The Pretest and Post test Mean and Standard deviation scores on 4Km run/ walks for time.

\begin{tabular}{|l|l|l|l|l|}
\hline & \multicolumn{1}{|c|}{$\begin{array}{c}\text { EXP A } \\
(6 \%) \text { Concentration }\end{array}$} & $\begin{array}{c}\text { EXP B } \\
(7 \% \text { Concentration })\end{array}$ & $\begin{array}{c}\text { EXP C } \\
(8 \% \text { Concentration })\end{array}$ & \multicolumn{1}{c|}{ CONTROL (0\%) } \\
\hline PRE & $8.35 \mathrm{~min}$ & $8.20 \mathrm{~min}$ & $8.29 \mathrm{~min}$ & $8.26 \mathrm{~min}$ \\
\hline SD & 1.0706 & 1.4539 & 1.7764 & 1.7053 \\
\hline POST & $7.63 \mathrm{mins}$ & $7.40 \mathrm{mins}$ & $7.28 \mathrm{mins}$ & $8.15 \mathrm{mins}$ \\
\hline SD & 1.6357 & 2.3279 & 2.1259 & 1.3836 \\
\hline
\end{tabular}

This clearly shows that the different concentrations of "gari" solution affected the experimental groups $\mathrm{A}, \mathrm{B}$, and $\mathrm{C}$ differently to some extent.

The Table 5 above shows the existence of significant difference of 4.46 between Pre and Post for experimental group A; 5.28 between Pre and Post for experimental group B; 8.33 between Pre and Post for experimental group $\mathrm{C}$; however no significant difference between Pre and Post-test score for group $\mathrm{D}$ which is the control group.

This also helps to confirm that the "gari" solution in post experimental group A, B and C significantly 
influenced the performance on the $4 \mathrm{~km}$ run/walk. While the absence of "gari" solution in Post D group did not have any significant effect.

Table 5: Comparison of intra-group Performance on 4km run/walk

\begin{tabular}{|c|c|c|c|c|c|c|}
\hline Variables & $\mathrm{N}$ & $X$ & SD & $\mathrm{df}$ & Calculated t-value & Critical t-value \\
\hline Pre A & 10 & 8.35 & 1.0706 & & & \\
\hline Post A & 10 & 7.63 & $\begin{array}{ll}1.6357 & 9\end{array}$ & $4.46^{*}$ & 2.262 & \\
\hline Pre B & 10 & 8.20 & 1.4539 & & & \\
\hline Post B & 10 & 7.40 & 2.32799 & $5.28 *$ & 2.262 & \\
\hline Pre C & 10 & 8.29 & 1.7764 & & & \\
\hline Post C & 10 & 7.28 & 2.12599 & 8.33* & 2.262 & \\
\hline Pre D & 10 & 8.26 & 1.7053 & & & \\
\hline Post D & 10 & 8.15 & $1.3836 \quad 9$ & 1.77 & 2.262 & \\
\hline
\end{tabular}

* Significant at 0.05 alpha level

\section{DISCUSSIONS}

In hypothesis 1 , the mean for the group A (pre is 8.40 minutes while post is 7.63 minutes). The table 4 also indicates the result of the t-test for this group. The calculated t-value of 4.46 is greater than the critical t-value of 2.262; therefore, the hypothesis is rejected. Showing that there is a significant difference between the endurance performance of school children in pre and post tests in experimental group $\mathrm{A}$ in a $4 \mathrm{~km}$ run/walk based on different concentration of Gari solution. This finding is in line with study that carbohydrate injection can enhance performance during prolonged exercise (Coggan and Swanson, 2002, Coyle and Montain, 2011).

Hypothesis 2 is rejected, because, calculated value of 5.28 is greater than the critical $t$-value of 2.26. The mean score of group B (pre is 8.20 while post is 7.40), It is therefore glaring that there existed a significant difference between the endurance performance of school children in the pre and post tests in experimental group in $4 \mathrm{~km}$ run/walk based on different concentration. In line with the present study is that of Fitzergald (2002) who also believes that athletic performances are enhanced by consuming beverages of various combinations of carbohydrates (glucose, sucrose, fructose, and glucose polymers) electrolytes (sodium potassium ,and chloride).
On hypothesis 3, based on the result from analysis that calculated tvalue of 8.33 is greater than the critical tvalue of 2.26, this clearly shows that the hypothesis is rejected. With the mean group C (pre is 8.28 minutes while post is 7.28 minutes), it can therefore be ascertained that there is a significant difference between the endurance performances of pre and post tests in experimental group $C$ in a $4 \mathrm{~km}$ run/walk on the bases of different concentrations of "Gari solutions. The outcome of this study is corroborates with Coyle and Montain ( 2002) in their study using 6\%, $7 \%$ and $8 \%$ glucose concentration also found that $8 \%$ concentration gave the best result in his study. This study is also in line with Coggan et al (1989) who concluded that carbohydrate injection improves performance primarily by maintaining the availability and oxidation of this critical fuel when endogenous carbohydrate stores are low.

Hypothesis 4 was accepted, because the calculated value of 1.77 is less than the critical table value of 2.262, at df 9 and 0.05 level of significant. This shows that there is no significant difference in pre and post test endurance performance among the students in Ilorin metropolis in $4 \mathrm{~km}$ run/walk. This depicts that for any significant improvement to be on the endurance performance of the students, there is need to administer a booster in form of carbohydrate solution to the students. 


\section{CONCLUSIONS}

Based on the findings of this study, the following conclusions were drawn

1. Prepared "gari" solution greatly improved the endurance performance of students in the experimental group as compared with those who did not take it.

2. Gari solution brought a positive significant difference in the result of the Pre-test and Post-test scores of the experimental groups.

3. The local electrolyte (gari solution) enhanced the endurance performances of the students at different levels of concentrations.

\section{RECOMMENDATIONS}

In view of the findings revealed and conclusions of this research, the following recommendations are made.

1. The local electrolyte (gari solution) should be encouraged by the coaches, sport handlers and used by the athletes instead of the foreign sport drinks.

2. The timing of administration of gari solution should be determined according to individual before drinking for competition.

3. People should catch vision on the production and how to hygienically package the local electrolyte (gari solution) with adequate preservation, so as to make our athletes and others who engage in endurance activity have easy access to such as a standard drink.

\section{REFERENCES}

Adeniyi, J. A. (1990). The role of sport in promoting national and international unity. A paper presented at citizenship and leadership training course at youth Camp, Yikpata. Kwara State.

American College of Sport Medicine (1991). Guidelines for exercise testing and prescription. (4 $4^{\text {th }}$ Ed.). Philadephia: Lea \& Febiger.

Araoye, M. O. (2003): Research methodology: with statistics for health and social science. Ilorin: Nathadex publishers.

Asiedu, J.J. (2009). Processing tropical crops. A technological approach. Hamsphire: Macmillan Education Ltd.

Brewer. J., Williams, C. \& Patton A., (2005). The influence of high carbohydrate diets on endurance running performance, European Journal of Applied Physiology 57. 698-706.

Cook, J. H. (2005). Cassava: New potential for a reflected crop. London: Westview Press.

Coggan, A. R. \& Swanson, S. C. (2002). Carbohydrate ingestion during prolonged exercise: Effects on metabolism: and performance: Exercise Sports Science (rev). 19:140.

Coyle, E. F., Hagberg, J. M, Hurley, B. F, Martin, W. H, Ehsani, A. A. \& Holloszy, J. O. (2011). Carbohydrate feedings during prolonged strenuous exercise can delay fatique. Journal of Applied Physiology. 55: $230-235$.

Coyle, E. F, \& Montain, S. I. (2002). Benefit of fluid replacement with carbohydrate during exercise. Medicine and Science in Sports and Exercise. 24 (9): 5324 -5330.

Fielding, R. A., Costill, D. L., Fink, W. J, King, D. S, Hargreaves , H. \& Kovaleski J. E. (2005). Effect of carbohydrate feeding frequency and dosage on muscle glycogen use during exercise. Medicine and Science in Sport and Exercise., 17: 472-476.

Fitzergald, P. (2002). Sport medicine advisors: Sport drinks. New York: Schenectady Regional Orthopedics.

Fox, E. L. (2009). The physiological basis for physical education and 
athletics ( $3^{\text {rd }}$ ed.) London: W. B. Sawka, M. N., Knowlton, R. G and Critz, Saunders Company.

Karim, O.R and Fasasi, O.S. (2009). Gari yield and chemical composition of cassava roots using traditional methods. African Crop Science Conference Proceedings, 9:329332.

Marieb, E. N. (2009). Human anatomy and physiology. ( $2^{\text {nd }}$ ed.) Redwood City, L. A. Benjamin-Cummings,

Nancy, C. (2006). Sport nutrition. Brookline; Sports Medical System Incorporated.

Nutritional Master (2011). Present knowledge in nutrition $\left(5^{\text {th }} \mathrm{ed}\right)$ Washington: Nutritional Foundation.

J. B. (2009): Thermal and circulatory responses to repeated bouts of prolonged running. Medicine and Science in Sport and Exercise. 11: 177-180.

Sloan A. W. (2005): Physiology: for students and teachers of physical education. London: Edward Arnold Publishers Ltd.

Talabi, A. E. (2000). Dietary “AIDS” for sports excellence: A Nigerian perspective. Health and Fitness Journal International. 1, (1)

Talabi, A. E. (2001). The application of oral rehydration therapy for athletics performance in the humid tropics. African Journal of Education. 6: 25-30. 